\title{
Current treatment options for postmenopausal vaginal atrophy
}

This article was published in the following Dove Press journal: International Journal of Women's Health

Iuliia Naumova'

Camil Castelo-Branco ${ }^{2}$

'Department of Obstetrics and Gynecology, Faculty of General Medicine Saratov State Medical University named after V.I. Razumovsky, Saratov, Russia; ${ }^{2}$ Institute Clinic of Gynecology, Obstetrics and Neonatology, Faculty of MedicineUniversity of Barcelona, Hospital Clinic-August Pi i Sunyer Biomedical Research Institute (IDIBAPS), Barcelona, Spain
Correspondence: Camil Castelo-Branco Institute Clinic of Gynecology, Obstetrics and Neonatology, Hospital Clinic, Villarroel 170, 08036 Barcelona, Spain

Tel +34932275436

Fax +39932279325

Email castelobranco@ub.edu
Abstract: Vulvovaginal atrophy (VVA) is a silent epidemic that affects up to $50 \%-60 \%$ of postmenopausal women who are suffering in silence from this condition. Hormonal changes, especially hypoestrogenism inherent in menopause, are characterized by a variety of symptoms. More than half of menopausal women are concerned about the symptoms of VVA, such as dryness, burning, itching, vaginal discomfort, pain and burning when urinating, dyspareunia, and spotting during intercourse. All these manifestations significantly reduce the quality of life and cause discomfort in the sexual sphere. However, according to research, only $25 \%$ of patients with the symptoms of VVA receive adequate therapy. This is probably due to the lack of coverage of this problem in the society and the insufficiently active position of specialists in the field of women's health regarding the detection of symptoms of VVA. Many patients are embarrassed to discuss intimate complaints with a specialist, which makes it difficult to verify the diagnosis in $75 \%$ of cases, and some patients regard the symptoms of VVA as manifestations of the natural aging process and do not seek help. Modern medicine has in the arsenal various options for treating this pathological condition, including systemic and topical hormone replacement therapy, the use of selective estrogen receptor modulators, vaginal dehydroepiandrosterone, use of lubricants and moisturizers, as well as non-drug therapies. Timely diagnosis and adequately selected therapy for the main symptoms of VVA lead to restoration and maintenance of the vaginal function and vaginal health.

Keywords: vulvovaginal atrophy, vaginal dryness, dyspareunia, menopause, hormonal replacement therapy, local estrogen, selective estrogen receptor modulator, vaginal dehydroepiandrosterone

\section{Introduction}

Menopause is a phenomenon that inevitably occurs in the life of every woman. The mean age of menopause in European countries is between 46.7 and 50.1 years. ${ }^{1}$ This period is characterized by the loss of hormonal function of the ovaries. With increased life expectancy, the impact of vulvovaginal atrophy (VVA) on the quality of life, sexual function, and pelvic floor health is becoming more evident in the present practice of medicine. Clinical manifestations of the menopausal syndrome are diverse and determined by the duration of hypoestrogenism. Genitourinary syndrome of menopause is one of the most frequent complaints referred by postmenopausal women. Genitourinary syndrome of menopause is a recent terminology that describes an assortment of exam findings and bothersome symptoms related to estrogen deficiency that involves changes in the labia, introitus, clitoris, vagina, urethra, and bladder. VVA is just a component of this general condition. Characterized by a chronic progressive course, VVA significantly impairs the quality of life and sexual health of women.

Women affected by this condition may present a variety of symptoms including vaginal and vulvar pain and irritation. Vaginal dryness due to hypoestrogenism 
can be accompanied by itching, burning, discharge, and dyspareunia. $^{2}$ Some women also develop fear of pelvic examinations. Frequency of occurrence of VVA, severity of pathological changes, and clinical course of the disease depend on the duration of postmenopause. In the first years after the termination of menstruation, involuntary changes in the vaginal mucosa are not very pronounced, and only $4 \%$ of women have clinical manifestations of this condition according to the literature. As the estrogen deficiency grows, dystrophic and atrophic changes develop in the vaginal mucosa, vulva, and other structures of the urogenital tract. Thus, in 7-10 years after the termination of menstruation, atrophic changes are observed in almost 50\% of women, and with time, their frequency increases to $73 \%-75 \%$ (while about $70 \%$ of women with symptoms of vaginal atrophy do not turn to doctors, considering it a natural condition).

Recently, the European Vulvovaginal Epidemiological Survey was carried out, in which $>2,000$ postmenopausal women were examined. Symptoms of VVA were detected in $90 \%$ of women. According to the results of the survey, the quality of life in this group of women was significantly lower in comparison to that of women of postmenopausal age without symptoms of VVA. ${ }^{3}$

The mucus membrane of the lower sections of the urogenital tract is very sensitive to the effects of estrogens.
A sufficient level of these hormones ensures a good blood supply to the vaginal mucosa and the optimal level of lubrication is maintained. ${ }^{4}$ Furthermore, estrogens may also induce proliferation of layers of vaginal wall epithelium as well as smooth muscle fibers and collagen maintaining the rugae of the vagina. ${ }^{5}$ By mingling, cells of stratified squamous epithelium, rich in glycogen, are a nutrient substrate for the bacteria of the vaginal microbiota. Vaginal microbiota is a dynamic variable system, represented by a variety of bacteria, the vital activity and balance of which provides vaginal homeostasis. The importance of microbiota in the formation of vaginal health cannot be underestimated. The dominant constituent of the vaginal microbiota is lactobacillus. Production of lactic acid, as a result of the vital activity of these bacteria, ensures the maintenance of the optimum low $\mathrm{pH}$ of the vaginal fluid, thus protecting from infections of the urogenital tract. The low $\mathrm{pH}$ of the vaginal fluid is also maintained by the active proton transport by the vaginal epithelium formed because of anaerobic glucose metabolism. ${ }^{6-9}$

Under hypoestrogenic conditions, the vaginal epithelium becomes thinner, its barrier function is lost, the vaginal folding decreases, the elasticity of the tissues decreases, and the secretory activity of the Bartholin glands decreases, which lead to traumatization of the vaginal mucosa and painful sensations (Figure 1). 5,10,11

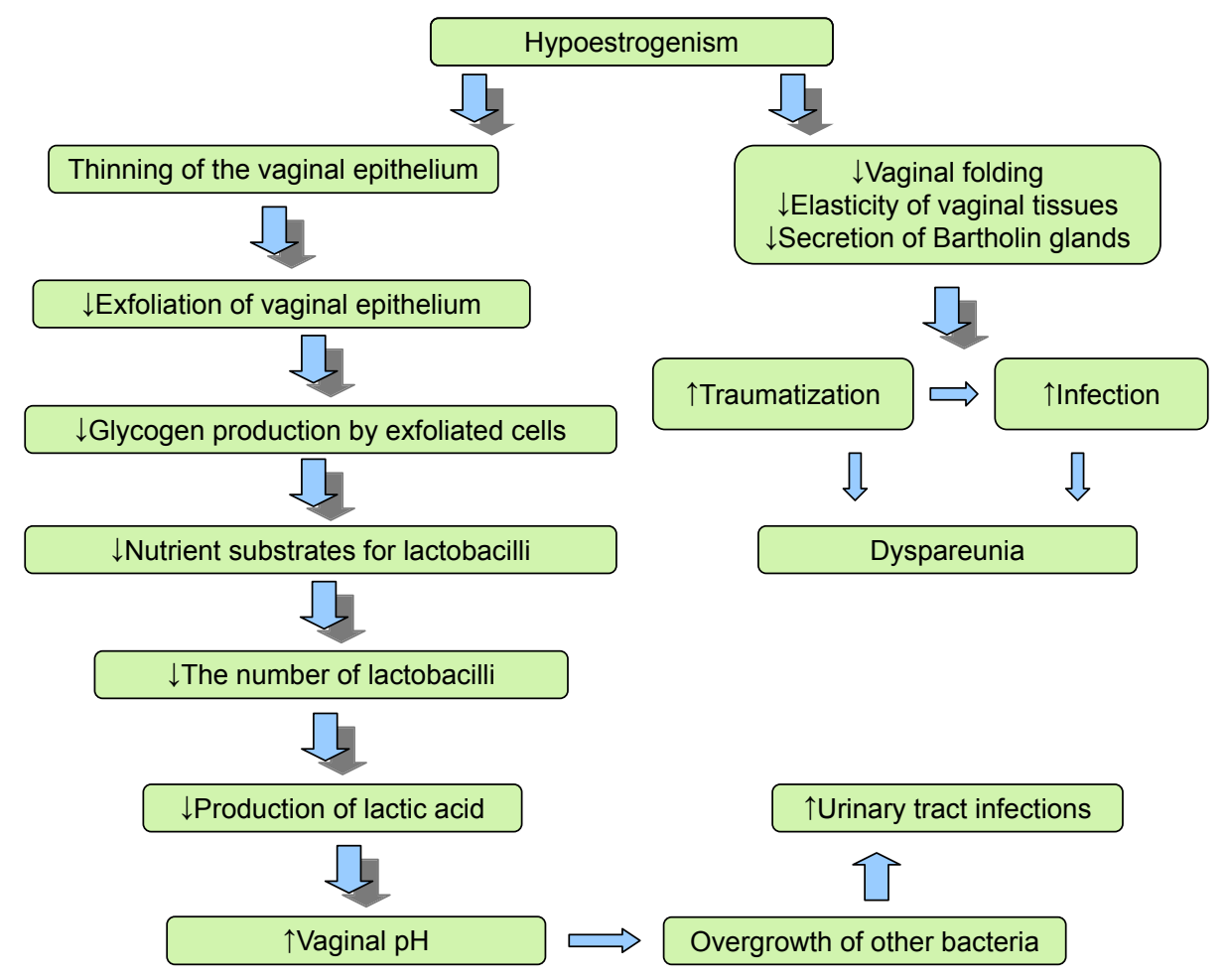

Figure I Cascade effects of the mechanism of VVA.

Abbreviation: VVA, vulvovaginal atrophy. 
In addition, under conditions of estrogen deficiency, the balance of the vaginal microbiota is disrupted, the pathogenic gram-negative fecal flora and other bacteria prevail in its composition, and the vagina develops a less acidic $\mathrm{pH}$, that is, from 5.5 to $6.8 .^{9,12}$ In studies by Brotman et al, a correlation between the nature of the vaginal microbiota, the low lactobacillus content, and the development of VVA was noticed. The data obtained by the authors demonstrate differences in the vaginal microbiota of pre-, peri-, and postmenopausal women. In the proposed hypothesis, the predominance of anaerobic flora in the vaginal environment plays a role in the development of VVA symptoms. ${ }^{13}$

\section{Clinical impact}

Clinically, VVA is manifested by dryness in the vagina, dyspareunia, vaginal discharge, itching, and pain., ${ }^{41}$

Dyspareunia leads to a decrease in sex drive and fear of sexual intercourse. As the frequency of coitus diminishes, vaginal lubrication declines further. ${ }^{15}$

Some women may already have narrowing of the vagina or manifestations of vaginismus, limiting the penetration into the vagina.

However, in some women with mild-to-moderate severity, VVA occurs asymptomatically and verification of diagnosis is possible only with vaginal examination. ${ }^{16}$

The diagnosis of VVA is made difficult by the low awareness of women about the pathological manifestations of the postmenopausal period and unwillingness/embarrassment to discuss the symptoms of an intimate character with the expert. In their study, Nappi and Kokot-Kierepa noted that only $4 \%$ of respondents associated their symptoms with the manifestations of menopause. ${ }^{17}$ Unfortunately, $75 \%$ of patients with the clinical manifestations of VVA do not seek help from specialists. ${ }^{5}$

According to Nappi et al, only $54 \%$ of menopausal women are willing to discuss their sexual health with a specialist and $33 \%$ of patients even refuse to answer questions. ${ }^{18}$

The experts in the field of women's health are faced with the task of early detection of VVA and the timely administration of etiopathogenetic treatment.

In terms of the survey, a detailed history of the patient with a suspicion of VVA should be conducted to identify the possible causes, including effects of irritants (lubricants, hygienic gels, soaps, spermicides), the use of antiestrogen drugs, advanced oophorectomy, or chemotherapy.

The diagnosis is confirmed by vaginal examination and colposcopy, wherein atrophic epithelium and thin, pale, and easily traumatized petechial hemorrhages can be detected.
It is necessary to carry out bacteriological studies, determine the acidity of the vaginal contents, perform cytological examination of the vaginal smears, and count the karyopicnotic index.

Differential diagnosis has to be performed with the conditions summarized in Table 1.

The main therapeutic goal in managing VVA is to relieve symptoms and restore the vaginal environment to a healthy premenopausal state. However, despite the high prevalence and negative impact on the quality of life, VVA is underreported by patients, undiagnosed by health care providers, and undertreated. Gynecologists should proactively start an open discussion with patients on urogenital symptoms. Treatment should be started as early as VVA occurs and should be maintained over time. As there are many treatment options, therapy should be individualized.

Table I Differential diagnosis of VVA

\begin{tabular}{|c|c|}
\hline Condition & Main symptoms and signs \\
\hline Vaginal infections & $\begin{array}{l}\text { Vaginal discharge (leukorrhea, } \\
\text { xanthorrhea), pruritus, bad smell }\end{array}$ \\
\hline Allergic reactions & $\begin{array}{l}\text { Redness, swelling, pruritus, } \\
\text { occasionally blistering, and pain }\end{array}$ \\
\hline Lichen planus & $\begin{array}{l}\text { Painful, red plaques or erosions with } \\
\text { white or violaceous borders; may } \\
\text { extend into vagina }\end{array}$ \\
\hline Lichen sclerosis & $\begin{array}{l}\text { Coalescing ivory and pink plaques in } \\
\text { butterfly of crinkled, wax-like tissue. } \\
\text { May result in labial and clitoral hood } \\
\text { agglutination }\end{array}$ \\
\hline $\begin{array}{l}\text { Ulcers and cracks in the } \\
\text { external genitalia associated } \\
\text { with systemic diseases: Behçet }\end{array}$ & $\begin{array}{l}\text { There are intensely painful, punched- } \\
\text { out ulcers, which are often bilateral, } \\
\text { with a yellow-white base and red } \\
\text { borders }\end{array}$ \\
\hline $\begin{array}{l}\text { Ulcers and cracks in the } \\
\text { external genitalia associated } \\
\text { with systemic diseases: Crohn }\end{array}$ & $\begin{array}{l}\text { Mixed inflammatory lesions, fissures, } \\
\text { and "knife-cut" ulcers of variable } \\
\text { severity. May progress into fistulae; } \\
\text { most commonly, in perianal or } \\
\text { rectovaginal sites. Marked painless } \\
\text { vulval edema may occur }\end{array}$ \\
\hline $\begin{array}{l}\text { Acute vulvar ulcers or } \\
\text { Lipschütz ulcers }\end{array}$ & $\begin{array}{l}\text { Acute painful genital ulcerations } \\
\text { of the vulva or lower vagina. } \\
\text { May appear in nonsexually active } \\
\text { adolescent girls or young women }\end{array}$ \\
\hline Other vulvovaginal ulcers & $\begin{array}{l}\text { Gluten enteropathy, systemic lupus } \\
\text { erythematosus, Stevens-Johnson } \\
\text { syndrome, pyoderma, pemphigus } \\
\text { vulgaris, pemphigoid, and so on }\end{array}$ \\
\hline $\begin{array}{l}\text { Tumors of the urogenital } \\
\text { tract }\end{array}$ & $\begin{array}{l}\text { Presented as multifocal red, white, } \\
\text { or dark raised or eroded neoplasm } \\
\text { lesions, or as solitary ulcer with } \\
\text { raised or indurated edge }\end{array}$ \\
\hline Extramammary Paget disease & $\begin{array}{l}\text { Brick red, scaly, eczematoid plaque } \\
\text { with sharply demarcated border and } \\
\text { sometimes a roughened surface }\end{array}$ \\
\hline
\end{tabular}

Abbreviation: VVA, vulvovaginal atrophy. 


\section{Women's perspectives on and options for treatment of genitourinary syndrome of menopause - VVA}

Treatment of VVA depends on the severity of the symptoms of the disease and on the preferences and expectations of women.

\section{Lubricants and moisturizers}

According to the generally accepted international standards, the first-line recommendations for the treatment of mild and moderate manifestations of VVA are nonhormonal vaginal lubricants that should be used before intercourse and vaginal moisturizers with a long-term effect that are used regularly (several times a week); in such cases, regular sexual activity is of importance.

This treatment option is also recommended for women for whom the use of vaginal estrogen preparations is unacceptable. ${ }^{19}$

Lubricants provide a short-term relief from vaginal dryness and discomfort during sexual intercourse.

They may be water, silicone, or oil based and are applied to the vulva, vagina, or penis before sexual activity. Lubricants with a water base have fewer side effects, which is an advantage compared to lubricants based on silicone. ${ }^{19}$ The literature contains sparse data on the safety of lubricants based on oils, the effect on motility of spermatozoa, and the properties of condoms. There is also evidence of an increased risk of developing bacterial vaginosis and vaginal candidiasis with the use of these medications. ${ }^{20-22}$

Vaginal moisturizers have a long-lasting effect in relieving the symptoms of VVA, enhancing moisturizing of the vaginal mucosa, and reducing the $\mathrm{pH}$. These drugs are prescribed on a regular basis: daily or every 2-3 days, depending on the extent of the symptoms. ${ }^{19}$ According to Chen et al, the use of hyaluronic acid vaginal gel every 3 days causes improvement in symptoms of vaginal dryness, comparable with the effect of topical estrogen therapy. ${ }^{23}$

When choosing lubricants and moisturizers, it is important that the product is similar to vaginal secretion in terms of osmolality, $\mathrm{pH}$, and composition. ${ }^{19}$

Vaginal lubricants and moisturizers can be used as needed in combination with other VVA treatments.

\section{Hormone therapy (local and systemic)}

Considering the cause (hypoestrogenism), and the pathogenesis of the development of VVA, the most logical choice for the treatment of this condition would be estrogen therapy. However, for most physicians and scientific societies, it is a second-line treatment after moisturizers and lubricants. Replenishment of estrogen deficiency can be carried out with hormonal preparations with systemic and local action, as well as with preparations of plant origin. According to the latest clinical guidelines for the management of patients with VVA, systemic or topical application of pharmacological estrogen preparations sufficiently and quickly improves the index of maturation and thickness of the vaginal mucosa, reduces the $\mathrm{pH}$ of the vagina, increases vaginal maturation index, and eliminates the symptoms of VVA. $5,8,10,24,25$

Systemic hormone replacement therapy (HRT) includes all preparations containing estradiol, estradiol valerate, or conjugated estrogens.

Systemic HRT is prescribed in the case of a combination of symptoms of urogenital atrophy with other symptoms of climacteric syndrome, as well as for the prevention and treatment of late-onset manifestations of the syndrome and its complications.

The local HRT includes preparations containing estradiol, as well as estriol. Local estrogen therapy is preferred in the presence of isolated urogenital disorders; the patients should be informed that the effect is achieved after 1-3 months of local estrogen therapy, and that they should be able to choose the drug that they consider most appropriate for them. ${ }^{8,24}$

Studies have shown that systemic HRT eliminates the symptoms of vaginal atrophy in $75 \%$ of cases, while local therapy does so in $80 \%-90 \%$ of cases. ${ }^{12}$

Estrogen therapy is prescribed after a clinical examination, identifying the risk factors for possible complications, and explaining the information to the patient. Low doses of estrogens are preferred for use, since the use of high doses of estrogen in menopausal age is associated with a high risk of hyperproliferative endometrial and adenocarcinoma. ${ }^{15}$

Absorption of low-dose vaginal estrogen preparations into the systemic blood stream is minimal and serum estradiol level does not exceed the physiological value for the postmenopausal period. ${ }^{26}$ Such a route of administration of drugs allows to avoid hepatic metabolism, which minimizes the risk of side effects inherent in systemic estrogen therapy and excludes the effects on the endometrium and breast tissue, and thus, there is no need to prescribe progesterone preparations for the prevention of endometrial hyperplasia and adenocarcinoma. Local estrogen therapy allows to quickly eliminate the symptoms of VVA, but it does not alleviate the vasomotor symptoms and reduce the risk of osteoporosis. 
According to the North American menopausal community, when taking low-dose vaginal estrogen preparations, the following ones occur: a decrease in the rugae of the vagina, an increase in the number of lactobacilli, and an improvement in the state of the vaginal epithelium and the epithelium of the urethra. ${ }^{4}$

Pharmaceutical estrogen-containing preparations for topical use are available in the form of a cream, tablets, and a vaginal estrogen-releasing ring which may contain estriol, conjugated equine estrogens, estradiol, or estrone (Table 2).

According to the 2006 Cochrane review, all forms of drug administration are equally effective in providing relief from vaginal dryness, dyspareunia, and pruritus. As well, there are no significant differences in the thickness of the endometrium, the incidence of endometrial hyperplasia, and side effects. ${ }^{25,27}$

However, an insignificant risk of vaginal bleeding has been described in all studies in which various methods of topical estrogen therapy have been used.

The choice of the form of administration of the drug is determined by the patient's preference.

The most commonly used form of local estrogen therapy is vaginal creams based on conjugated equine estrogens and $17 \mathrm{~b}$ estradiol; they provide a good moisturizing effect. However, the amount of cream administered can vary, exceeding the recommended daily dosage, which is particularly undesirable for patients at high risk. According to data of Kingsberg et al, several women experience discomfort when using vaginal cream, finding it messy. ${ }^{28}$

If more controlled dosing of estrogen is required, the drug of choice may be vaginal tablets containing $10 \mathrm{mg}$ of estradiol.
During the first 2 weeks of use, the daily use of the above-mentioned drug groups is recommended, followed by a transition to maintenance therapy with a dose of two to three times a week. ${ }^{15}$

Sustained-release estradiol vaginal rings are preferred for women for whom daily use of drugs is unacceptable. Vaginal rings are inserted for up to 90 days and can be independently installed and removed by the patient. However, depending on the daily dose of estrogens, such systems can facilitate not only urogenital symptoms, but also vasomotor manifestations of the climacteric syndrome. ${ }^{26}$

The use of vaginal rings is not recommended in women with prolapse of the genitals. It is also necessary to warn a woman about the possible expulsion of the vaginal ring.

In the studies of Constantine et al, ${ }^{29}$ Simon et al, ${ }^{30}$ and Pickar et al, ${ }^{31}$ a good result regarding the rapid relief from the symptoms of VVA was noted when using gel capsules with estradiol, released at a dose of 4, 10, and $25 \mu \mathrm{g}$. At the same time, the absorption of the drug into the systemic circulation and the maximum concentration of estradiol in the serum were significantly lower in comparison with the use of vaginal tablets. ${ }^{29-31}$ The authors noted relief from the main symptoms of VVA for a few weeks after the use of vaginal capsules, but in most cases, it took up to 12 weeks of therapy to completely relieve the symptoms. However, clinical observations of the use of this group of low-dose estrogens are limited to 1 year.

Several clinical studies have also noted improvements in urinary symptoms, such as urgency, frequency, nocturia, and stress and urgency urinary incontinence. ${ }^{25}$

Very interesting are the data published by Santen, where various variants of local estrogen therapy (low-, intermediate-,

Table 2 Hormonal therapy for management of vulvovaginal atrophy

\begin{tabular}{|c|c|c|c|c|}
\hline $\begin{array}{l}\text { Route of } \\
\text { administration }\end{array}$ & Medication & $\begin{array}{l}\text { Pharmacological } \\
\text { preparations }\end{array}$ & Initial dosage & Maintenance dosage \\
\hline \multirow[t]{2}{*}{ Vaginal cream } & Estradiol-17b & Estrace $0.01 \%$ & $\begin{array}{l}0.5-1 \mathrm{~g} \text { daily for the } \\
\text { first } 2 \text { weeks }\end{array}$ & $\begin{array}{l}0.5-1 \mathrm{~g} \text { one to three times } \\
\text { weekly }\end{array}$ \\
\hline & $\begin{array}{l}\text { Conjugated } \\
\text { estrogens }\end{array}$ & Premarin $0.625 \mathrm{mg} / \mathrm{g}$ & $\begin{array}{l}0.5-1 \mathrm{~g} \text { daily for the } \\
\text { first } 2 \text { weeks }\end{array}$ & $\begin{array}{l}0.5-1 \mathrm{~g} \text { one to three times } \\
\text { weekly }\end{array}$ \\
\hline Vaginal tablets & $\begin{array}{l}\text { Estradiol } \\
\text { hemihydrate }\end{array}$ & Vagifem, Yuvafem & $\begin{array}{l}10 \mu g \text { once daily for } \\
\text { the first } 2 \text { weeks }\end{array}$ & One or two times per week \\
\hline Vaginal capsules & $\begin{array}{l}\text { Estradiol-17b } \\
\text { softgel capsules }\end{array}$ & TX-004HR & $\begin{array}{l}4 / 10 / 25 \mu g \text { daily for } \\
2 \text { weeks }\end{array}$ & One or two times per week \\
\hline \multirow[t]{2}{*}{ Vaginal ring } & Estradiol-I7b & Estring & $\begin{array}{l}2 \mathrm{mg} \text { (releases } \\
7.5 \mu \mathrm{g} \text { daily) }\end{array}$ & Insert for 90 days \\
\hline & Estradiol acetate & Femring & $\begin{array}{l}\text { 12.4/24.8 mg (releases } \\
0.05 / 0.1 \mu \mathrm{g} \text { daily) }\end{array}$ & Insert for 90 days \\
\hline Oral & $\begin{array}{l}\text { SERM } \\
\text { ospemifene }\end{array}$ & $\begin{array}{l}\text { Osphena } \\
\text { Senshio }\end{array}$ & 60 mg daily & 60 mg daily \\
\hline
\end{tabular}

Abbreviation: SERM, selective estrogen receptor modulator. 
and high-dose) and their adsorption into the systemic circulation are considered. The author compared the peak concentrations of estrogens and the "chronic concentration" of estrogens in the blood plasma as a result of adsorption with prolonged use. According to data analysis of $>30$ studies, the use of low-dose vaginal estrogens $(7.5 \mu \mathrm{g}$ silastic vaginal ring and a $10 \mu \mathrm{g}$ estradiol tablet [eg, VagifemR]) showed adsorption to the systemic circulation, but during long-term administration the estradiol levels were $<20 \mathrm{pg} / \mathrm{mL} .{ }^{32} \mathrm{How}-$ ever, according to several authors, against the background of long-term use of low-dose local estrogens, systemic effects on bone resorption and serum lipid were observed. ${ }^{33,34}$

The intermediate- and high (systemic)-dose regimens include $25 \mu \mathrm{g}$ of higher estradiol preparations. The intermediate- and high-dose vaginal estradiol preparations are well absorbed, and they maintain the concentration of estrogens in the plasma corresponding to the period of premenopause. $^{32}$

When administering local and systemic estrogen preparations, it is necessary to remember the side effects of drugs associated with systemic adsorption and carefully assess the risks of complications. Excess estrogen levels in postmenopausal women are associated with an increased risk of heart disease, breast cancer, thromboembolic complications, and cerebrovascular diseases. ${ }^{35}$ Preference should be given to low-dose local estrogens, especially if the therapy is prescribed to aged patients.

However, in spite of the vast amount of positive data showing improvement of vaginal health and sexual function with estrogens and moisturizers, recent data by Mitchell et al generate controversy as they have shown no benefits on comparing both with placebo. ${ }^{36}$ Though the authors note that the study was conducted in a homogeneous population of patients, in contrast to other studies that limit the inclusion of a woman with a high vaginal $\mathrm{pH}$ in the study, all postmenopausal women with symptoms of moderate or severe VVA were included in this study. Evaluation of the effectiveness of therapy was limited to a 12 -week period.

\section{Selective estrogen receptor modulators}

Selective estrogen receptor modulators (SERMs) are another option for VVA treatment among women in whom estrogen preparations are contraindicated.

SERMs are structurally different and interact with intracellular estrogen receptors in the target organs as agonists or antagonists of estrogens.

In 2013, the drug of this group (ospemifene) was approved for use by the US Food and Drug Administration
(FDA) and is now successfully used in USA and Europe. The literature has already accumulated sufficient reports on the use of oral ospemifene.

Ospemifene has relatively weak estrogenic and antiestrogenic effects in classical hormonal tests, has an anti-osteoporosis effect, and reduces the level of total cholesterol.

A comparable effect with vaginal estrogens has been noted regarding alleviating the symptoms of vaginal atrophy and dyspareunia, improving the vaginal epithelium and $\mathrm{pH}$ of the vagina. ${ }^{37}$ The results of the studies with ospemifene show significant increase in the percentage of surface cells of the vaginal epithelium and a decrease in the percentage of parabasal cells and a decrease in vaginal $\mathrm{pH}^{38}$

Constantine et al, in their double-blind, placebo-controlled study, found the efficacy and safety within 1 year of using ospemifene. No cases of endometrial cancer were reported and only $<1 \%$ of patients had endometrial hyperplasia. The incidence of thromboembolism associated with ospemifene in the pivotal studies was comparable to placebo; however, as a SERM, the class effect regarding the increased risk of venous thrombosis should be considered and this drug should be avoided in patients with an increased risk of venous thrombosis. ${ }^{39}$

Lasofoxifene is new third-generation SERM that binds to both estrogen receptor types and is currently not approved for use by the FDA. ${ }^{40}$ Lasofoxifene has a pronounced positive effect on the state of the vaginal epithelium and $\mathrm{pH}$ and provides relief from the main symptoms of VVA in comparison to taking placebo. ${ }^{38}$

A number of studies have shown the high efficacy of lasofoxifene in improving bone mineral density, as well as reducing the risk of coronary heart disease and stroke and alleviating the symptoms of VVA. ${ }^{41-44}$

A tissue-specific estrogen complex is now being developed, including a combination of SERM (bazedoxifene) with conjugated estrogens. In the literature, there is evidence of the drug causing significant relief from the symptoms of genitourinary syndrome without the development of endometrial hyperplasia. ${ }^{45,46}$

The effect of tamoxifen in the vaginal epithelium is not well established; however, most of the data demonstrated that tamoxifen exerts antiestrogenic effect on the vaginal epithelium. Raloxifene slightly increased the percentage of vaginal superficial cells and decreased the percentage of parabasal cells; however, raloxifene did not improve the symptom of dyspareunia. ${ }^{47}$

\section{Vaginal dehydroepiandrosterone}

Dehydroepiandrosterone (DHEA) is a steroid prohormone in the biosynthetic pathway of testosterone and estradiol. 
The vaginal metabolism of DHEA into estrogens/testosterone leads to the activation of estrogen and androgen receptors in the three layers of the vaginal wall, including the fibers of the basal membrane collagen and the muscle wall, but the absence of aromatase in the normal endometrium does not lead to its stimulation. ${ }^{48}$ The levels of estradiol and testosterone in the serum may have minimal increases, without clinical significance presumably because of local inactivation. There is a slight increase in the serum concentration of DHEA sulfate.

In a new prospective, randomized, double-blind clinical trial, Labrie et al confirmed the local beneficial effect of intravaginal DHEA (prasterone) on the symptoms of mild/ severe dyspareunia, the most frequent manifestation of genitourinary syndrome in postmenopausal women. ${ }^{49}$

For the daily vaginal use of DHEA, Intrarosa ${ }^{\circledR}$ (prasterone) $(6.5 \mathrm{mg})$ was recently approved by the FDA for use in the treatment of dyspareunia.

\section{Laser therapies}

Recently introduced in the treatment of VVA, laser vaginal therapy has demonstrated effectiveness as well as high satisfaction among patients and health care providers. Data on the procedure were first published in 2014 and use of fractional microablative carbon dioxide laser therapy for genitourinary surgery was approved by the FDA.

Laser therapy improves the vascularization of the vaginal mucosa, stimulates the synthesis of new collagen and matrix basic substance in the connective tissue, thickens the vaginal epithelium with the formation of new papillae, replenishes glycogen in the vaginal epithelium, allows restoring the balance of the mucosa and therefore improves the symptoms of atrophy caused by a lack of estrogen. ${ }^{50-52}$

Salvatore et al also noted a significant improvement in the quality of life and sexual activity when laser therapy was used in women with VVA. ${ }^{51}$

In the study of Salvatore et al, $85 \%$ of women who were previously not sexually active due to genitourinary syndrome of menopause symptoms regained a normal sexual life at 12 weeks following therapy. ${ }^{53}$ The positive effect in the treatment of women with VVA can be achieved by combining hormonal and non-hormonal methods of treatment. It is important not to forget about the positive effect of sexual intercourse on the improvement of vaginal health. For the women who do not have regular sexual intercourse or have vaginal narrowing, the phenomenon of vaginismus, gradual careful stretching of the vagina with special dilators using lubricants is recommended. It can play an important role in restoring and maintaining the vaginal function. Then, the resumption of regular sexual activity will help to maintain vaginal health. Many women with these disorders benefit from the exercises that strengthen the muscles of the pelvic floor. In those patients, the use of vaginal estrogens before and after the expansion of the vagina and/or therapy to strengthen the pelvic muscles may be useful.

\section{Conclusion}

VVA complicates the course of postmenopausal period in more than half of the women. Manifestations of VVA bring discomfort in the daily life of a woman, worsening the quality of life and vaginal health. Timely active detection of this pathological condition and providing adequately selected therapy can prevent the progress of the disease and significantly improve the quality of life and sexuality of women.

\section{Disclosure}

The authors report no conflicts of interest in this work.

\section{References}

1. Cuadros J, Llaneza P, Mateu S. Demografia y epidemiologia del climaterio en España En: Libro blanco de la menopausia en España EMISA, editor. Madrid; 2000:15-33.

2. Castelo-Branco C, Cancelo MJ. Compounds for the treatment of atropic vaginitis. Expert Opin Ther Pat. 2008;18(12):1385-1394.

3. Palacios S, Nappi RE, Bruyniks N, et al. The European Vulvovaginal Epidemiological Survey (EVES): prevalence, symptoms and impact of vulvovaginal atrophy of menopause. Climacteric. 2018;21(3): 286-291.

4. North American Menopause Society. The role of local vaginal estrogen for treatment of vaginal atrophy in postmenopausal women: 2007 position statement of The North American Menopause Society. Menopause. 2007;14(3 Pt 1):355-369.

5. Palacios S. Atrophy Murogenital. Managing urogenital atrophy. Maturitas. 2009;63(4):315-318.

6. Apolihina I, Gorbunova E. Clinical and morphological aspects of vulvovaginal atrophy. Medical Council. 2014;9:109-117.

7. Palacios S, Castelo-Branco C, Currie H, et al. Update on management of genitourinary syndrome of menopause: A practical guide. Maturitas. 2015;82(3):308-313.

8. Castelo-Branco C, Cancelo MJ, Villero J, Nohales F, Juliá MD. Management of post-menopausal vaginal atrophy and atrophic vaginitis. Maturitas. 2005;52 Suppl 1(1):46-52.

9. Godha K, Tucker KM, Biehl C, Archer DF, Mirkin S. Human vaginal pH and microbiota: an update. Gynecol Endocrinol. 2018;34(6): $451-455$.

10. Sturdee DW, Panay N; International Menopause Society Writing Group. Recommendations for the management of postmenopausal vaginal atrophy. Climacteric. 2010;13(6):509-522.

11. Basaran M, Kosif R, Bayar U, Civelek B. Characteristics of external genitalia in pre- and postmenopausal women. Climacteric. 2008;11(5): 416-421.

12. Goldstein I. Recognizing and treating urogenital atrophy in postmenopausal women. J Womens Health. 2010;19(3):425-432.

13. Brotman RM, Shardell MD, Gajer P, et al. Association between the vaginal microbiota, menopause status, and signs of vulvovaginal atrophy. Menopause. 2014;21(5):450-458.

14. Wines N, Willsteed E. Menopause and the skin. Australas J Dermatol. 2001;42(3):149-160.

15. Gandhi J, Chen A, Dagur G, et al. Genitourinary syndrome of menopause: anoverview of clinical manifestations, pathophysiology, etiology, evaluation, andmanagement. Am J Obstet Gynecol. 2016;215(6):704-711. 
16. Davila GW, Singh A, Karapanagiotou I, et al. Are women with urogenital atrophy symptomatic? Am J Obstet Gynecol. 2003;188(2):382-388.

17. Nappi RE, Kokot-Kierepa M. Vaginal Health: Insights, Views \& Attitudes (VIVA) - results from an international survey. Climacteric. 2012;15(1):36-44.

18. Nappi RE, Panay N, Bruyniks N, et al. The clinical relevance of the effect of ospemifene on symptoms of vulvar and vaginal atrophy. Climacteric. 2015;18(2):233-240.

19. Edwards D, Panay N. Treating vulvovaginal atrophy/genitourinary syndrome of menopause: how important is vaginal lubricant and moisturizer composition? Climacteric. 2016;19(2):151-161.

20. Sandhu RS, Wong TH, Kling CA, Chohan KR. In vitro effects of coital lubricants and synthetic and natural oils on sperm motility. Fertil Steril. 2014;101(4):941-944.

21. Voeller B, Coulson A, Bernstein G, Nakamura R. Mineral cause of rapid deterioration of latex. Contraception. 1989;39(1):95-102.

22. Brown JM, Hess KL, Brown S, et al. Intravaginal practices and risk of bacterial vaginosis and candidiasis infection among a cohort of women in the United States. Obstet Gynecol. 2013;121(4):773-780.

23. Chen J, Geng L, Song X, et al. Evaluation of the efficacy and safety of hyaluronic acid vaginal gel to ease vaginal dryness: a multicenter, randomized, controlled, open-label, parallel-group, clinical trial. J Sex Med. 2013;10(6):1575-1584.

24. Pickar JH. Emerging therapies for postmenopausal vaginal atrophy. Maturitas. 2013;75(1):3-6.

25. Rahn DD, Carberry C, Sanses TV, et al. Vaginal estrogen for genitourinary syndrome of menopause: a systematic review. Obstet Gynecol. 2014;124(6):1147-1156.

26. Management of symptomatic vulvovaginal atrophy: 2013 position statement of The North American Menopause Society. Menopause. 2013; 20(9):888-902.

27. Suckling J, Lethaby A, Kennedy R. Local oestrogen for vaginal atrophy in postmenopausal women. Cochrane Database Syst Rev. 2006;(4): CD001500.

28. Kingsberg SA, Krychman M, Graham S, Bernick B, Mirkin S. The Women's EMPOWER Survey: Identifying Women's Perceptions on Vulvar and Vaginal Atrophy and Its Treatment. J Sex Med. 2017;14(3): 413-424.

29. Constantine GD, Simon JA, Pickar JH, et al. The REJOICE trial: a phase 3 randomized, controlled trial evaluating the safety and efficacy of a novel vaginal estradiol soft-gel capsule for symptomatic vulvar and vaginal atrophy. Menopause. 2017;24(4):409-416.

30. Simon JA, Archer DF, Constantine GD, et al. A vaginal estradiol softgel capsule, TX-004HR, has negligible to very low systemic absorption of estradiol: Efficacy and pharmacokinetic data review. Maturitas. 2017; 99:51-58.

31. Pickar JH, Amadio JM, Bernick BA, Mirkin S. Pharmacokinetic studies of solubilized estradiol given vaginally in a novel softgel capsule. Climacteric. 2016;19(2):181-187.

32. Santen RJ. Vaginal administration of estradiol: effects of dose, preparation and timing on plasma estradiol levels. Climacteric. 2015;18(2): 121-134.

33. Naessen T, Berglund L, Ulmsten U. Bone loss in elderly women prevented by ultralow doses of parenteral 17beta-estradiol. Am J Obstet Gynecol. 1997;17734(1):115-119.

34. Naessen T, Rodriguez-Macias K, Lithell H. Serum lipid profile improved by ultra-low doses of 17 beta-estradiol in elderly women. J Clin Endocrinol Metab. 2001;86(6):2757-2762.
35. Manson JE, Chlebowski RT, Stefanick ML, et al. Menopausal hormone therapy and health outcomes during the intervention and extended poststopping phases of the Women's Health Initiative randomized trials. JAMA. 2013;310(13):1353-1368.

36. Mitchell CM, Reed SD, Diem S, et al. Efficacy of vaginal estradiol or vaginal moisturizer vs placebo fot treating postmenopausal vulvo vaginal symptoms: a randomized clinical trial. JAMA Intern Med. 2018;178(5):681-690.

37. Paton DM. Ospemifene for the treatment of dyspareunia in postmenopausal women. Drugs Today. 2014;50(5):357-364.

38. Mirkin S, Pickar JH. Selective estrogen receptor modulators (SERMs): a review of clinical data. Maturitas. 2015;80(1):52-57.

39. Constantine GD, Goldstein SR, Archer DF. Endometrial safety of ospemifene: results of the phase $2 / 3$ clinical development program. Menopause. 2015;22(1):36-43.

40. Pinkerton JV, Stanczyk FZ. Clinical effects of selective estrogen receptor modulators on vulvar and vaginal atrophy. Menopause. 2014; 21(3):309-319.

41. Moffett A, Ettinger M, Bolognese M, et al. Lasofoxifene, a next generation SERM, is effective in preventing loss of BMD and reducing LDLC in postmenopausal women. J Bone Miner Res. 2004;19:96.

42. Mcclung MR, Siris E, Cummings S, et al. Prevention of bone loss in postmenopausal women treated with lasofoxifene compared with raloxifene. Menopause. 2006;13(3):377-386.

43. Cummings S, Eastell R, Ensrud K. The effects of lasofoxifene on fractures and breast cancer: 3 year results from the PEARL trial. J Bone Miner Res. 2008;23:81.

44. Gennari L, Lasofoxifene GL. Lasofoxifene, a new selective estrogen receptor modulator for the treatment of osteoporosis and vaginal atrophy. Expert Opin Pharmacother. 2009;10(13):2209-2220.

45. Kagan R, Williams RS, Pan K, Mirkin S, Pickar JH. A randomized, placebo- and active-controlled trial of bazedoxifene/conjugated estrogens for treatment of moderate to severe vulvar/vaginal atrophy in postmenopausal women. Menopause. 2010;17(2):281-289.

46. Lobo RA, Pinkerton JV, Gass ML, et al. Evaluation of bazedoxifene/ conjugated estrogens for the treatment of menopausal symptoms and effects on metabolic parameters and overall safety profile. Fertil Steril. 2009;92(3):1025-1038.

47. Komm BS, Mirkin S. Evolution of the tissue selective estrogen complex (TSEC). J Cell Physiol. 2013;228(7):1423-1427.

48. Portman DJ, Labrie F, Archer DF, et al. Lack of effect of intravaginal dehydroepiandrosterone (DHEA, prasterone) on the endometrium in postmenopausal women. Menopause. 2015;22(12):1289-1295.

49. Labrie F, Archer DF, Koltun W, et al. Efficacy of intravaginal dehydroepiandrosterone (DHEA) on moderate to severe dyspareunia and vaginal dryness, symptoms of vulvovaginal atrophy, and of the genitourinary syndrome of menopause. Menopause. 2016;23(3):243-256.

50. Abrahamse H. Regenerative medicine, stem cells, and low-level laser therapy: future directives. Photomed Laser Surg. 2012;30(12): 681-682.

51. Salvatore S, Athanasiou S, Candiani M, Stefano S, Stavros A, Massimo C. The use of pulsed $\mathrm{CO} 2$ lasers for the treatment of vulvovaginal atrophy. Curr Opin Obstet Gynecol. 2015;27(6):1-8.

52. Hutchinson-Colas J, Segal S. Genitourinary syndrome of menopause therapy. Maturitas. 2015;82:342-345.

53. Salvatore S, Nappi RE, Parma M, et al. Sexual function after fractional microablative $\mathrm{CO}_{2}$ laser in women with vulvovaginal atrophy. Climacteric. 2015;18(2):219-225. 
International Journal of Women's Health

Dovepress

\section{Publish your work in this journal}

The International Journal of Women's Health is an international, peerreviewed open-access journal publishing original research, reports, editorials, reviews and commentaries on all aspects of women's healthcare including gynecology, obstetrics, and breast cancer. The manuscript management system is completely online and includes Visit http://www.dovepress.com/testimonials.php to read real quotes from published authors.

Submit your manuscript here: http://www.dovepress.com/international-journal-of-womens-health-journal 